\title{
Comparison of the Galleria baiting technique and a direct extraction method for recovering Steinernema (Nematoda: Rhabditida) infective- stage juveniles from soil
}

\author{
Dieter Sturhan $^{1}$ and Zdeněk Mráček ${ }^{2}$ \\ ${ }^{1}$ Biologische Bundesanstalt für Land- und Forstwirtschaft, Institut für Nematologie und Wirbeltierkunde, Toppheideweg 88 , \\ 48161 Münster, Germany; \\ ${ }^{2}$ Laboratory of Insect Pathology, Institute of Entomology, Academy of Sciences of the Czech Republic, Branišovská 31,37005 \\ České Budějovice, Czech Republic
}

Key words: entomopathogenic nematodes, Steinernema, baiting, extraction, methods, soil, Czech Republic, Germany

\begin{abstract}
Forty soil samples from forests and other biotopes in Germany and the Czech Republic were studied for the presence of entomopathogenic nematodes using the Galleria bait method at the same time as a sieving-decanting method for direct extraction of infective-stage juveniles. Five Steinernema species were recovered from the samples from Germany and four species from the samples from Czechia. All five species were recovered with both methods, but the baiting technique was generally less effective and mixtures of species were frequently undetected. The direct extraction method provided quantitative estimates of infective-stage juvenile density but no information on their infectivity or on morphological characters of adults, and nematode cultures could not be established.
\end{abstract}

The baiting technique with larvae of the greater wax moth, Galleria mellonella (L.), is the method most commonly used for recovering infective-stage juveniles of entomopathogenic nematodes from soil (Bedding and Akhurst 1975, Mráček 1980). The efficiency of this method had been increased using several consecutive baiting rounds (Fan and Hominick 1991) and by baiting at two temperatures (Mráček and Bečvár 2000). Methods commonly used for extraction of terrestrial nematodes from soil samples were shown to provide better quantitative estimates of infective-stage juveniles of entomopathogenic nematodes (Curran and Heng 1992). However, in most surveys to estimate the natural occurrence of steinernematids and heterorhabditids, the live bait technique with Galleria traps has been applied. Only exceptionally have methods of direct extraction of infective-stage juveniles from soil been used on a large scale (Sturhan 1996, 1999). Obvious differences in results obtained with both methods appear to indicate that certain species of Steinernema and Heterorhabditis may be "overlooked" with Galleria baiting so that while $G$. mellonella is one of the most susceptible hosts, it cannot be used universally for recovering all species of entomopathogenic nematodes. For example, Steinernema scapterisci Nguyen et Smart, 1990 develops poorly in Galleria larvae (Nguyen and Smart 1990).

In the present study, soil samples from sites where several Steinernema species had been found, were used to compare the efficiency of the Galleria baiting method with that of direct extraction of infective-stage juveniles from the soil. The steinernematids included the species $S$. intermedium (Poinar, 1985) and Steinernema sp. B, which had been rarely or not at all recorded in surveys based on the Galleria bait technique (Hominick et al. 1995, Miduturi et al. 1997), but were commonly recovered using methods of direct extraction from soil (Sturhan 1999, Sturhan and Lišková 1999).

\section{MATERIALS AND METHODS}

Thirty soil samples were taken in five small forests at the western border of the town of Münster, Germany, in April and May 1999. Ten samples originated from one forest and five each from the other four forests (Table 1). The prevailing trees at the five sites, which were located over a distance of $3 \mathrm{~km}$, were Quercus robur, Fagus silvatica and Carpinus betulus. Each sample of about $1000 \mathrm{ml}$ of soil consisted of four subsamples taken from the upper $30 \mathrm{~cm}$ soil layer around the stem of a single tree, mostly from oak. Another ten soil samples of approximately the same volume each were collected in April 1999 in the South Bohemian basin close to the village of Kardašova Řečice from deciduous forests, solitaire tree stands (oak, lime, birch, spruce, pine) and meadows. Each bulk sample consisted of five soil cores taken at each habitat. For the laboratory tests, each soil sample from both countries was mixed and divided into two parts. One part was used for the baiting method and the other for direct isolation of the nematodes from soil.

For the baiting studies, two $250 \mathrm{ml}$ subsamples of each soil sample were placed in Petri dishes $(13.5 \mathrm{~cm}$ diameter, $1.7 \mathrm{~cm}$ depth) and kept in incubators at 15 and $22^{\circ} \mathrm{C}$, respectively. The $G$. mellonella larvae used as baits were each set in a small iron mesh pocket at the bottom in the centre of each Petri dish. 
Mortality of G. mellonella was assessed after 5 days. Dead Galleria larvae were divided in two batches. One was dissected to obtain adult nematodes of the second generation while the second batch was used for culturing on a water trap to obtain infective juveniles. "Negative" soil samples and samples with nematode infection, but without successful maturation of adults and development of new juveniles, were exposed repeatedly to fresh Galleria larvae. Adults and infective juveniles were heatkilled in Ringer's solution and fixed overnight in TAF fixative, transferred to permanent glycerin mounts, and then identified under a light microscope using morphological characters.

For the second series of samples, a sieving-decanting method was employed with final isolation of the nematodes from the sieving debris using a Baermann funnel with cotton filter. For this method, which is commonly applied for the extraction of plant-parasitic and soil nematodes (Southey 1986), $250 \mathrm{ml}$ soil each was used. The nematode suspensions obtained were fixed, checked for the presence of entomopathogenic nematodes using an inverted light microscope, and the number of Steinernema specimens was determined. Species identification was mostly done at high microscopical magnification using morphological characters of the infective-stage juveniles (Sturhan in Hominick et al. 1997, and unpublished).

\section{RESULTS}

Infective-stage juveniles of Steinernema were present in all five sampled forests in Germany (Table 1). Of the total of 30 samples, 23 contained entomopathogenic nematodes. Among the 10 samples from the Czech Republic, 7 were positive for steinernematids (Table 2). Five Steinernema species were identified in the samples from Münster: S. intermedium, S. affine (Bovien, 1937), S. kraussei (Steiner, 1923), S. feltiae (Filipjev, 1934) and the undescribed Steinernema sp. B (cf. Sturhan 1999). From two to five different species were found in each sampled forest. Four species occurred at the sampling sites in Czech Kardašova Řečice. Besides $S$. affine and $S$. kraussei the two species $S$. intermedium and Steinernema sp. B were found, both only recently recorded for the Czech Republic (Mráček et al. 1999). The maximum number of Steinernema specimens isolated from a single $250 \mathrm{ml}$ soil sample was 500 (Table 1, sample 11).

A comparison of the two methods employed shows that the results about determining presence of entomopathogenic nematodes are almost identical. Only for three

Table 1. Recovery of Steinernema infective-stage juveniles by the Galleria baiting technique (GB) and direct extraction (DE) in soil samples from five forests (I-V) in Germany (see text).

\begin{tabular}{|c|c|c|c|c|c|c|c|c|c|c|c|}
\hline \multirow[t]{2}{*}{ Site } & \multirow{2}{*}{$\begin{array}{c}\text { Sample } \\
\text { No. }\end{array}$} & \multicolumn{2}{|c|}{$\begin{array}{l}\text { Steinernema } \\
\text { intermedium }\end{array}$} & \multicolumn{2}{|c|}{$\begin{array}{l}\text { Steinernema } \\
\text { affine }\end{array}$} & \multicolumn{2}{|c|}{$\begin{array}{l}\text { Steinernema } \\
\text { kraussei }\end{array}$} & \multicolumn{2}{|c|}{$\begin{array}{l}\text { Steinernema } \\
\text { feltiae }\end{array}$} & \multicolumn{2}{|c|}{$\begin{array}{c}\text { Steinernema } \\
\text { sp. B }\end{array}$} \\
\hline & & GB & $\mathrm{DE}$ & GB & $\mathrm{DE}$ & GB & $\mathrm{DE}$ & GB & $\mathrm{DE}$ & GB & $\mathrm{DE}$ \\
\hline \multirow{10}{*}{ I } & 1 & + & $62 *$ & - & - & - & 12 & - & - & - & - \\
\hline & 2 & + & 50 & - & - & - & - & - & - & - & - \\
\hline & 3 & - & - & - & - & - & - & - & - & - & - \\
\hline & 4 & - & 8 & - & - & + & 3 & - & - & - & - \\
\hline & 5 & + & 53 & - & - & - & - & - & - & - & - \\
\hline & 6 & - & 1 & - & - & - & - & - & - & + & 21 \\
\hline & 7 & + & 2 & - & - & - & - & - & - & - & - \\
\hline & 8 & - & - & - & - & - & - & - & - & - & - \\
\hline & 9 & + & 21 & - & - & - & - & + & 41 & - & - \\
\hline & 10 & - & - & + & 2 & - & - & - & 2 & - & - \\
\hline \multirow{5}{*}{ II } & 11 & + & 400 & - & - & + & 100 & - & - & - & - \\
\hline & 12 & - & - & - & - & - & - & - & - & - & - \\
\hline & 13 & - & - & - & - & + & 67 & - & - & - & - \\
\hline & 14 & - & - & - & - & + & 94 & - & - & - & - \\
\hline & 15 & - & - & - & - & + & 40 & - & - & - & - \\
\hline \multirow{5}{*}{ III } & 16 & - & - & - & 1 & - & - & - & 1 & - & - \\
\hline & 17 & + & 108 & - & - & - & - & - & - & - & - \\
\hline & 18 & - & - & - & - & + & 85 & - & - & - & - \\
\hline & 19 & - & - & - & - & + & 72 & - & - & - & - \\
\hline & 20 & - & - & - & - & + & 43 & - & - & - & - \\
\hline \multirow{5}{*}{ IV } & 21 & - & - & - & - & - & - & - & - & - & - \\
\hline & 22 & - & - & - & - & + & 20 & - & - & - & 140 \\
\hline & 23 & - & - & - & - & - & - & - & - & + & 30 \\
\hline & 24 & - & - & - & - & - & - & - & - & - & - \\
\hline & 25 & - & - & - & - & - & - & - & - & - & - \\
\hline \multirow{5}{*}{ V } & 26 & - & 20 & - & - & + & 30 & - & - & - & - \\
\hline & 27 & - & 330 & - & - & + & 30 & - & - & - & - \\
\hline & 28 & - & 20 & - & - & + & 30 & - & - & - & - \\
\hline & 29 & - & - & - & - & - & - & - & - & - & - \\
\hline & 30 & + & 20 & - & - & - & - & - & - & - & - \\
\hline
\end{tabular}

* Number of specimens in $20 \mathrm{ml}$ of soil. 
Table 2. Recovery of Steinernema infective-stage juveniles by the Galleria baiting technique (GB) and direct extraction (DE) in soil samples from the Czech Republic (see text).

\begin{tabular}{|c|c|c|c|c|c|c|c|c|}
\hline \multirow{3}{*}{ Sample no. } & \multicolumn{2}{|c|}{$\begin{array}{c}\text { Steinernema } \\
\text { intermedium }\end{array}$} & \multicolumn{2}{|c|}{$\begin{array}{c}\text { Steinernema } \\
\text { affine }\end{array}$} & \multicolumn{2}{c|}{$\begin{array}{c}\text { Steinernema } \\
\text { krausse }\end{array}$} & \multicolumn{2}{c|}{$\begin{array}{c}\text { Steinernema } \\
\text { sp. B }\end{array}$} \\
\cline { 2 - 8 } & GB & DE & GB & DE & GB & DE & GB & DE \\
\hline 1 & - & - & - & - & - & - & + & 3 \\
2 & - & - & - & - & - & 2 & - & - \\
3 & & - & - & - & - & - & - & - \\
4 & - & - & - & - & + & 9 & - & - \\
5 & - & 1 & - & - & + & 1 & - & - \\
6 & - & - & - & - & + & 38 & - & - \\
7 & - & - & + & 4 & - & - & - & - \\
8 & - & - & - & - & - & - & - & - \\
9 & - & - & - & - & - & 3 & - & - \\
10 & - & - & - & - & - & - & - & - \\
\hline
\end{tabular}

samples the direct extraction method yielded steinernematids that had not been recovered by the baiting method (Table 1, sample 16; Table 2, samples 2 and 9). In these three samples the Steinernema population densities were low. For 11 of the 23 positive samples from Germany, the direct extraction method revealed the coexistence of two Steinernema species within the same sample (Table 1, nos. 1, 4, 6, 9, 10, 11, 16, 22, 26, 27 and 28 ), with a similar observation for one of the samples from the Czech Republic (Table 2, no. 5). The presence of several Steinernema species within a soil sample was only occasionally shown using the baiting method (Table 1 , samples 9 and 11), but was documented for $30 \%$ of the samples by direct extraction (Tables $1+2$ ).

\section{DISCUSSION}

From the results obtained in the present study it is evident that all five Steinernema species are recoverable from soil using the baiting technique with Galleria mellonella larvae. This is in contradiction to common experience (Spiridonov, Ehlers and others, pers. comm.) that species such as $S$. intermedium and the undescribed Steinernema sp. B could not be recovered using Galleria baiting from soil samples from which numerous infective juveniles had been isolated by direct extraction. And there is also the fact that, e. g., S. intermedium and Steinernema sp. B, which are among the most common steinernematids recovered in Germany by direct extraction, have been only rarely or not at all found in neighbouring countries in surveys done by the baiting technique. It is still an open question if there are differences in the "suitability" of Galleria larvae as a bait and that, e. g., species such as $S$. intermedium and Steinernema sp. B are only rarely recovered using Galleria as a bait. Results given in Table 1 for samples 22, 26, 27 and 28 appear to indicate this, but this is not supported by the data obtained for sample no. 1 , in which $S$. intermedium was recovered by Galleria baiting but not $S$. kraussei. Mainly due to the fact that species mixtures were mostly not detected with the
Galleria traps, the number of records of each Steinernema species is considerably higher for direct extraction from soil than for the live bait technique (Table 3 ).

Table 3. Numbers of Steinernema spp. recoveries in 40 soil samples by the Galleria baiting technique (GB) and direct extraction (DE).

\begin{tabular}{|l|c|c|}
\hline Nematode species & GB & DE \\
\hline S. intermedium & 8 & 14 \\
S. affine & 2 & 3 \\
S. kraussei & 15 & 18 \\
S. feltiae & 1 & 3 \\
S. sp. B & 3 & 4 \\
\hline Total records & 29 & 42 \\
\hline
\end{tabular}

Low Steinernema population densities were "overlooked" in several cases with the baiting technique, despite the two soil subsamples used per site had about the double volume of those used for direct extraction. It is well known that not all infective-stage juveniles present in a soil sample can invade a bait and raise infections at any time (cf. Fan and Hominick 1991).

The results show that the presence of entomopathogenic nematodes in soil is best evaluated by methods of direct extraction of the infective-stage juveniles from soil samples, that probably all Steinernema (and Heterorhabditis) species will be recovered using such methods, that mixtures of species can easily be detected and that precise estimates of population densities are possible. When the nematode suspensions extracted from soil samples are fixed, a careful microscopical analysis is possible any time. The application of this method, however, requires experience for detection of entomopathogenic nematodes in suspensions of, possibly, several thousand of soil nematodes. Hence, this method requires more labour per sample compared to a bioassay. Also, good knowledge on identification of species based on morphological characters of the infective-stage juveniles 
is required. Using the baiting technique, males will generally be available to support or enable species identification and this method will also usually result in living laboratory cultures for consecutive studies. While direct extraction reveals only the presence of entomopathogenic nematodes in soil, the bait method demonstrates their infectivity. Hence, the method used depends on the objectives of a survey, and no single method is without some limitations or compromises (Hominick et al. 1996).

Acknowledgements. This study was supported by the Grant Agency of the Czech Republic, grant No. 206/96/0031, and the COST 819 project by funding a short-term mission to Zdeněk Mráček. We are grateful to Dorothee Suttorp, Münster; and Lenka Kropáčová, České Budějovice, for their technical assistance, and Bill Hominick for comments on the manuscript.

\section{REFERENCES}

BEDDING R.A., AKHURST R.J. 1975: A simple technique for the detection of insect parasitic nematodes in soil. Nematologica 21: 109-110.

CURRAN J., HENG J. 1992: Comparison of three methods for estimation the number of entomopathogenic nematodes present in soil samples. J. Nematol. 24: 170-176.

FAN X., HOMINICK W.M. 1991: Efficiency of the Galleria (wax moth) baiting technique for recovering infective stages of entomopathogenic rhabditids (Steinernematidae and Heterorhabditidae) from sand and soil. Rev. Nématol. 14: 381-387.

HOMINICK W.M., BRISCOE B.R., del PINO F.G., JIAN HENG, HUNT D.J., KOZODOY E., MRÁČEK Z., NGUYEN K.B., REID A.P., SPIRIDONOV S., STOCK P., STURHAN D., WATURU C., YOSHIDA M. 1997: Biosystematics of entomopathogenic nematodes: current status, protocols and definitions. J. Helminthol. 71: 271-298.

HOMINICK W.M., REID A.P., BOHAN D.A., BRISCOE B.R. 1996: Entomopathogenic nematodes: Biodiversity, geographical distribution and the Convention on Biological Diversity. Biocontr. Sci. Technol. 6: 317-331.

HOMINICK W.M., REID A.P., BRISCOE B.R. 1995: Prevalence and habitat specificity of steinernematid and heterorhabditid nematodes isolated during soil surveys of the UK and the Netherlands. J. Helminthol. 69: 27-32.

MIDUTURI J.S., WAEYENBERGE L., MOENS M. 1997: Natural distribution of entomopathogenic nematodes (Heterorhabditidae and Steinernematidae) in Belgian soils. Russ. J. Nematol. 5: 55-65.
MRÁČEK Z. 1980: The use of "Galleria traps" for obtaining nematode parasites of insects in Czechoslovakia (Lepidoptera: Nematoda, Steinernematidae). Acta Entomol. Bohemoslov. 77: 378-382.

MRÁČEK Z., BEČVÁŘ S. 2000: Insect aggregations and entomopathogenic nematode occurrence. Nematology 2: 297-301.

MRÁČEK Z., BEČVÁŘ S., KINDLMANN P. 1999: Survey of entomopathogenic nematodes from the families Steinernematidae and Heterorhabditidae (Nematoda: Rhabditida) in the Czech Republic. Folia Parasitol. 46: 145-148.

NGUYEN K.B., SMART G.C., Jr. 1990: Steinernema scapterisci n. sp. (Rhabditida: Steinernematidae). J. Nematol. 22: 187-199.

SOUTHEY J.F. (Ed.) 1986: Laboratory Methods for Work with Plant and Soil Nematodes. Her Majesty's Stationery Office, London, $202 \mathrm{pp}$.

STURHAN D. 1996: Jahreszeitliches Vorkommen, Horizontalund Vertikalverteilung entomopathogener Nematoden auf einer Ackerfläche. Mitt. Biol. Bundesanst. LandForstwirtsch. Berl.-Dahlem 317: 35-45.

STURHAN D. 1999: Prevalence and habitat specificity of entomopathogenic nematodes in Germany. Proc. Workshop held at Todi, Perugia, Italy, 16 to 29 May 1995. European Commission, COST 819, Luxembourg, pp. 123-132.

STURHAN D., LIŠKOVÁ M. 1999: Occurrence and distribution of entomopathogenic nematodes in the Slovak Republic. Nematology 1: 273-277. 